\title{
Huschner, Wolfgang, Rexroth, Frank, Gestiftete Zukunft im mittelalterlichen Europa. Festschrift für Michael Borgolte zum 60. Geburtstag
}

\section{Olivier Richard}

\section{OpenEdition}

\section{Journals}

Édition électronique

URL : http://journals.openedition.org/ifha/2163

DOI : 10.4000/ifha.2163

ISSN : 2198-8943

Éditeur

IFRA - Institut franco-allemand (sciences historiques et sociales)

Référence électronique

Olivier Richard, « Huschner, Wolfgang, Rexroth, Frank, Gestiftete Zukunft im mittelalterlichen Europa. Festschrift für Michael Borgolte zum 60. Geburtstag », Revue de l'IFHA [En ligne], Date de recension, mis en ligne le 01 janvier 2010, consulté le 22 septembre 2020. URL : http://journals.openedition.org/ifha/ 2163 ; DOI : https://doi.org/10.4000/ifha.2163

Ce document a été généré automatiquement le 22 septembre 2020.

(CIFHA 


\title{
Huschner, Wolfgang, Rexroth, Frank, Gestiftete Zukunft im mittelalterlichen Europa. Festschrift für Michael Borgolte zum 60. Geburtstag
}

\author{
Olivier Richard
}

Le titre de ces mélanges, "Avenir fondé dans l'Europe médiévale » résume bien l'entreprise : il associe les deux grands thèmes de recherche du professeur berlinois ici honoré, Michael Borgolte : les fondations (Stiftungen), qu'il a jadis qualifiées de " phénomène social total ", et l'Europe, à laquelle il s'est intéressé plus récemment, en particulier la diversité de l'Europe médiévale. Cet ouvrage collectif, qui rassemble des contributions de ses élèves, est donc divisé en deux grandes sections : « Europe » et « fondations ". Bien sûr, à l'intérieur de chacune de ces parties, les thèmes et les méthodes sont très variés. Dans la première partie, c'est bien la diversité qui est mise en avant, religieuse ou ethnique, mais aussi les marges de l'Europe. S. Esders traite des «frontières » de l'Empire romain d'Orient du IVe au VIIe siècle, en reconsidérant l'intégration des peuples fédérés dans l'Empire, leur christianisation et les redéfinitions de l'ethnicité que ces processus impliquent. J. Rüdiger examine le Holstein aux alentours de 1200 en tant que « frontier area », un espace disputé où apparaissent des lignes de faille multiples plutôt que ne se crée progressivement une société mixte. D. Waßenhoven présente un récit de voyage, s'apparentant à un guide du pèlerin vers Rome et Jérusalem, rédigé par l'abbé islandais Nikulás Bergsson vers 1155, dont il fournit une traduction en annexe. Une autre région marginale de l'Europe chrétienne, la Prusse, est l'objet de la contribution de M. Brauer, qui s'intéresse à la dénonciation $\mathrm{du}$ « culte du bouc » (sans doute une fête où des animaux étaient tués et mangés, et non pas " sacrifiés ») par les dirigeants luthériens - théologiens chrétiens mais aussi étrangers au pays - lors de la transformation du territoire de l'ordre Teutonique en duché héréditaire luthérien en 1525. Il est également question des relations des Occidentaux chrétiens avec les autres dans les contributions de B. Scheller et J. Schiel. Le premier s'intéresse aux rapports entre les campagnes de prédication des ordres 
mendiants en direction des juifs et les activités de l'Inquisition, dans la seconde moitié du XIIIe siècle, en comparant ces phénomènes en Aragon, France, royaume de Naples et comté de Provence ; il conclut que les campagnes de conversions ont eu des conséquences graves, car elles conduisaient forcément à des retours au judaïsme et ainsi à la persécution. Dans un article très stimulant, qui présente une esquisse de ce que sera sa thèse de doctorat, la seconde traite de la vision par les Dominicains de l'invasion mongole au XIIIe siècle et de la prise de Constantinople en 1453, et parle de " destruction productive ", dans la mesure où les deux événements obligèrent les Dominicains à revoir leur vision du monde. K. Wolf ferme cette section sur l'Europe en se demandant si le mythe de Troie, reconnu aujourd'hui comme " européen ", pouvait déjà avoir un tel potentiel unificateur au Moyen Âge, ce qui la conduit à revisiter les recherches des médiévistes sur les mythes.

2 La seconde partie mêle travaux monographiques et synthèses comparatives. W.E. Wagner commence avec une réflexion sur les services anniversaires que Charles le Chauve fonda pour commémorer des événements de sa vie ou celle de membres de sa famille, à la façon des empereurs romains fêtant l'anniversaire de leur accession au pouvoir par exemple ; Walafrid Strabo aurait présenté cette pratique de fondation à Charles, selon W.E.W. qui apporte de nouveaux arguments en faveur de cette thèse remontant à Ernst Kantorowicz. C. Moddelmog remet en cause la pertinence du concept de Eigenkirche (" église privée ») ; elle considère, après Borgolte, qu'il s'agit en fait de fondations, et met en pratique son idée dans son examen des fondations de couvents féminins en Saxe aux IXe et Xe siècles. La souplesse de la pratique sociale qu'est la fondation est au cœur de l'article de T. Geelhaar, qui compare les fondations de Megisti Lavra sur le mont Athos en 963 et du New Minster à Winchester en 901, et les solutions trouvées dans les deux cas pour assurer la continuité de l'institution. T. Lohse révise à l'aide de l'analyse d'une liste d'anniversaires (qu'il édite en annexe) l'opinion traditionnelle d'une crise de la collégiale SS.-Simon-et-Judée de Goslar au XIIIe siècle. F. Rexroth présente le projet étonnant de Pierre Dubois, avocat du roi sous Philippe le Bel, de créer un fonds alimenté par des confiscations pour financer une " fondation TerreSainte ». Ses objectifs auraient été de reconquérir la Palestine mais aussi de mettre en place dans toute la Chrétienté latine un système d'écoles où élèves des deux sexes auraient été préparés à la vie outre-mer. On retourne en Allemagne avec l'article de W. Huschner qui retrace la fondation du couvent de clarisses de Ribnitz par Henri II de Mecklembourg (1323/24-1331), malgré l'opposition des bourgeois comme du clergé séculier local. Enfin R. Lusiardi associe les deux thèmes principaux de l'ouvrage dans sa synthèse comparative sur "famille et fondation au Moyen Âge ", qui embrasse tout l'espace de la chrétienté occidentale.

3 On le voit : ces mélanges, qui reprennent beaucoup d'idées de Borgolte, sont extrêmement intéressants, grâce à la diversité des époques, régions, thèmes et sources abordés, mais aussi grâce au souci commun de présenter les méthodes mises en œuvre et d'expliquer les concepts utilisés.

Olivier Richard (Université de Haute-Alsace, Mulhouse) 